\title{
Una lectura sobre las organizaciones de base del movimiento obrero argentino (1955-1973)
}

\author{
Alejandro Schneider
}

UNLP-UBA

Durante las décadas de 1950 y 1970 el movimiento obrero argentino desempeñó un papel protagónico dentro de la sociedad. Según la mayoría de los estudios historiográficos sobre el período, la clase trabajadora ostentó un lugar determinante en la estructura social producto del importante crecimiento del sector manufacturero. Corresponde indicar que esta coyuntura estuvo, a su vez, circunscripta alrededor de los diferentes intentos, por parte de la clase dominante, de superar el modelo de industrialización de bienes de consumo final. A tal fin, uno de los principales objetivos buscados fue el de cambiar el mercado laboral consolidado en las décadas anteriores; fundamentalmente, modificando las condiciones de trabajo de la clase obrera industrial. De este modo, el periodo también se lo puede observar como un proceso histórico signado por un constante campo de conflicto entre las fuerzas del capital y las del trabajo.

En este escenario, los enfrentamientos decisivos fueron los que se desplegaron por el control de las condiciones y el ritmo de producción en el seno de los establecimientos fabriles. En ese ámbito, el principal papel fue el desempeñado por las diferentes instancias de representación directa de los trabajadores: los delegados, los cuerpos de delegados y las comisiones internas. En primera y última instancia, el rumbo de las diferentes politicas económicas fue también una disputa de poder que se expresó dentro de los talleres y las fábricas, entre patrones y obreros, en donde los diferentes gobiernos tampoco fueron ajenos. En este sentido, el intento de transformar el modelo social de acumulación de capital requirió tanto para los empresarios como para los gobernantes la tarea imperiosa de disciplinar al movimiento laboral; en particular, se buscó limitar el poder los organismos de base como condición necesaria para modificar la organización y los tiempos de la producción.

En el transcurso de esos años, las organizaciones de base ejercieron 
diversas tareas en el seno de los establecimientos: entre otras, primordialmente, se destacaron por defender a los trabajadores frente a las arbitrariedades patronales. Sin embargo, su influencia real y su alcance dependió de la lucha de clases antes que de cualquier norma oral o escrita. Por otro lado, si bien fueron el principal nexo de comunicación entre las jerarquías sindicales y los trabajadores en los lugares de empleo, su vínculo no fue siempre de sumisión con la dirigencia. En numerosas oportunidades, sus acciones tendieron a resquebrajar la verticalidad y disciplina de los gremios y, en no pocas circunstancias, quebraron los acuerdos firmados por las cúpulas laborales con los empresarios y los gobiernos. Sin embargo, más allá de estas características, coincidimos con la perspectiva de Adolfo Gilly (1986), quien reflexiona sobre el papel que potencialmente -a nivel político- pueden desempeñar las comisiones internas y los cuerpos de delegados en su crítica al sistema capitalista. En este sentido, en determinadas coyunturas de las décadas de 1960 y 1970, esta posibilidad de impugnación ha sido advertida por los sectores dominantes, como lo hemos analizado en otros ensayos (Pozzi y Schneider, 2000; Schneider, 2006, 2009).

Por otra parte, el análisis del comportamiento de la clase trabajadora y las medidas de fuerza que protagonizó no deben ser comprendidos como el mero resultado de factores económicos. Lejos de esa estrecha mirada, se busca entender que en la actividad gremial también intervienen ideas y valores desarrollados a partir de la experiencia hecha como sujeto colectivo. Los obreros constituyen su identidad y su conciencia sobre la base de su experiencia y de los enfrentamientos con las otras clases, a partir de las percepciones que poseen de sí y de los demás actores sociales en un ámbito permeado por constantes conflictos. De esta forma, la actuación sindical adquiere una mejor comprensión si se la examina como una parte integrante de la cultura obrera y de las diversas identidades politicas que disputan propuestas en esos espacios.

Cuestiones tales como la necesidad de la organización, la solidaridad, el orgullo de un oficio, la igualdad en las remuneraciones, la dignidad de las condiciones de labor y, sobre todo, el reconocimiento de que los trabajadores constituyen una clase distinta, con diferentes intereses, fueron algunos de los rasgos culturales que contribuyeron a su identidad como sujeto social. De ahí que dichas percepciones fueran propias de la clase obrera, de manera independiente de las ideologías politicas que profesaba o adhería. Esto también se expresó en una profunda conciencia sobre la necesidad de pertenecer a un sindicato y, a su vez, de contar con diferentes órganos de representación (comisiones internas, cuerpos de delegados) para hacerse escuchar, defenderse y poder obtener sus reivindicaciones. Al igual que en la conformación de la cultura y la conciencia obrera, la explotación capitalista en las fábricas, producto 
de las relaciones de producción, fue la base primigenia que permitió consolidar la identificación y la pertenencia a un sindicato y sus diversas instancias intermedias. Con el tiempo, los trabajadores fueron adoptando la entidad gremial como una herramienta básica e indispensable en su quehacer; ya fuese para el amparo de sus intereses laborales o como un instrumento que le servía para mejorar su desempeño.

El presente artículo intenta reflexionar sobre el papel que cumplieron la clase obrera y sus organismos de base fabril, entre 1955 y 1973, en defensa de las conquistas materiales y simbólicas obtenidas en los años anteriores. En este sentido, el estudio nos permite iluminar algunas cuestiones significativas sobre el comportamiento de los trabajadores frente a la ofensiva patronal y gubernamental del periodo. Corresponde subrayar que estas instancias de representación no tuvieron a lo largo de esa coyuntura una evolución lineal ni armónica, su desarrollo estuvo en permanente tensión con el capital, su antagonista histórico por naturaleza. Por otro lado, su análisis nos proporciona un conjunto de elementos probatorios que discuten la mirada que arguye que, en esos años, existió una "derrota" en el movimiento laboral (James, 1990). Por último, no por eso menos importante, consideramos que no se puede comprender el alto nivel de conflictividad social y el elevado grado de combatividad clasista que presentan los obreros tras el Cordobazo sin observar la notable experiencia de lucha y organización adquirida en los momentos previos.

\section{La impugnación obrera a la Revolución Libertadora}

El proceso de surgimiento y conformación de estas instancias de representación de trabajadores en el seno de los talleres y fábricas se remonta a la década del 30 del siglo pasado. Como ha sido explicado por Hernán Camarero (2007) y Diego Ceruso (2010), las mismas se expandieron entre los obreros metalúrgicos, textiles y de la construcción. Asimismo, su génesis estuvo en íntima vinculación con la actividad explícita desarrollada por el Partido Comunista Argentino.

Años más tarde, durante las dos primeras presidencias de Juan D. Perón (1946-1955), estas organizaciones de base se extendieron al conjunto del movimiento obrero, al calor del aumento de la movilización social y del amparo de la legislación centrada en torno a la Ley de Asociaciones Profesionales de 1945. Según Louise Doyon (1984, 2006), durante ese período, las comisiones internas se encargaron de controlar la aplicación de la reglamentación laboral, se convirtieron en el canal de comunicación entre los gremios y los trabajadores y, principalmente, se abocaron a la defensa de los derechos de estos últimos en los lugares de empleo. Sin embargo, sus funciones y sus tareas no fueron siempre 
bien aceptadas por los empresarios y el gobierno, en particular durante su segundo mandato. Como demuestra Marcos Schiavi (2008), éstas protagonizaron un importante número de protestas en abierta oposición a las medidas de racionalización de la producción impulsadas por la cartera económica justicialista. Su extendida influencia y su significativa presencia en el interior de los establecimientos fabriles fueron un motivo de preocupación para la patronal y las autoridades.

Tras el derrocamiento a Perón, estas inquietudes se convirtieron en una tarea de primer orden para la Revolución Libertadora; en poco tiempo, ésta se abocó a erradicar los beneficios sociales, económicos, legales y simbólicos logrados por los trabajadores. Ante ello, los obreros se atrincheraron para defender sus conquistas, sus formas de organización y el lugar que habían obtenido en la sociedad. La experiencia y la conciencia, legados de varias décadas de protestas con sucesivos regímenes, se manifestaron en estos enfrentamientos y en los que signaron los siguientes veinte años de historia argentina.

La clase obrera, en los principales centros fabriles, respondió y enfrentó -en forma autónoma- el golpe de estado de 1955. La ausencia de una dirección sindical y/o política que estuviese dispuesta a enfrentar consecuentemente el alzamiento militar hizo que la contienda asumiera (en los primeros meses) un carácter desorganizado, anárquico y, sobre todo, espontáneo. Abandonada por la conducción del peronismo y por un importante sector de la jefatura sindical, desde los lugares de empleo y de residencia los trabajadores iniciaron una serie de experiencias de resistencia clandestina que planteó graves problemas a la gobernabilidad del régimen.

El panorama se agravó a partir de las políticas económicas impulsadas por el gobierno de Pedro E. Aramburu. A pocas horas de asumir, con el objetivo de racionalizar las tareas e intentar incrementar los niveles de productividad obrera, la dictadura procuró atomizar la gestión sindical, debilitando los cuerpos de delegados y las comisiones internas. Una de las primeras medidas ordenadas fue la intervención militar de la Confederación General de Trabajo (CGT) y de numerosos sindicatos adheridos a ella. Esta reglamentación se acompañó con numerosas persecuciones y detenciones; junto con ello se modificó la norma que establecía el principio de sindicato único por actividad. Acompañando a estas prescripciones, el mandatario se propuso destruir el pilar que sostenía todo el andamiaje laboral: los organismos de base fabril. En ellos no sólo se concentraba el último bastión obrero que frenaba las ambiciones empresariales sino que también simbolizaban la contracara del poder de la clase dominante en el ámbito del trabajo.

En forma paralela, en el transcurso de esos años, comenzó a darse un debate en el seno de la clase dominante sobre la conveniencia o no 
de destruir estas instancias de representación. En términos generales, se impuso el criterio de que las mismas eran necesarias para mantener la organización y la disciplina gremial debido a que su anulación podía perjudicar todo el proceso productivo y las relaciones obrero-patronales. Pero, más allá de estas consideraciones, existía un común acuerdo entre los empresarios y el gobierno de reglamentar y limitar sus funciones.

Frente a los embates de la dictadura y de las empresas, los trabajadores respondieron con numerosos paros y sabotajes, que en su dinámica no sólo quebraron las medidas dispuestas por la cartera económica sino que, más importante aún, contribuyeron a la reorganización de la propia clase. En esas circunstancias confluyeron una serie de conflictos originados alrededor del aumento de los ritmos de producción, las formas de reordenamiento del empleo en los lugares de trabajo, la preservación de la organización gremial, el atraso en el cobro de sueldos y la defensa de los operarios despedidos.

El conflicto de los trabajadores metalúrgicos, en los últimos meses de 1956, fue un caso testigo de esas luchas: en él convergieron la resistencia obrera a la ofensiva dictatorial y empresarial, la dirigencia formada en el periodo anterior y el surgimiento de un nuevo activismo, con los límites que mostraban estos procesos. La huelga metalúrgica mostró un alto despliegue de combatividad, pese a no tener una dirección homogénea y centralizada. Este fue uno de los elementos que la caracterizó y, en cierta forma, la limitó en su accionar. No obstante, si algo dejó la protesta fue que permitió consolidar la figura de Augusto T. Vandor como hombre fuerte del gremio y, luego, como dirigente del conjunto del movimiento sindical a nivel nacional.

Por otra parte, el conjunto de estas acciones estimularon una notable recomposición de las bases gremiales: como consecuencia nacieron nuevos cuerpos de delegados y comisiones internas. Este proceso de renovación fue ejecutado en forma inesperada. A ello contribuyeron los resquicios legales provistos por el gobierno y el alto grado de experiencia gremial que ostentó buena parte del proletariado argentino. Como resultado emergió una nueva camada de activistas sindicales con posturas más intransigentes y combativas, en comparación con la existente bajo la segunda presidencia de Perón. Sin embargo, más allá de esta novel militancia gremial, el fenómeno fue encauzado y dirigido por líderes que contaban con una vasta experiencia burocrática en el manejo de las asociaciones profesionales, por ende -en numerosas circunstanciaspracticaron y mantuvieron un cierto control en sus organizaciones. $\mathrm{Si}$ bien en los principales gremios industriales hubo algunas medidas de fuerza que no redundaron en los resultados salariales esperados, los trabajadores fueron adquiriendo, en el transcurso de esos años, un notable saldo organizativo que se tradujo en la formación de nuevos 
agrupamientos laborales. Este proceso empezó a consolidarse, en 1957, con el nacimiento de la Comisión Intersindical, primero, y luego con las 62 Organizaciones, bajo la égida de líderes gremiales formados durante el peronismo.

El surgimiento de este agrupamiento, que reemplazó a la intervenida CGT, constituyó un fenómeno trascendente para el movimiento obrero porque le permitió dotarse de una dirección centralizada en el ámbito nacional para enfrentar al régimen castrense. Su conformación representó la máxima instancia de organización y permanencia que proporcionó la clase obrera durante esos años; las otras formas de lucha que se dieron, como la conformación de comandos o los levantamientos cívico-militares, tendieron a diluirse; o bien, si continuaron, perdieron con el tiempo toda efectividad. No obstante, cabría indicar que, pese a este papel opositor, desde su origen esta entidad nació dirigida por hombres que contaban con un amplio manejo burocrático en sus respectivas asociaciones gremiales. De ahi que, rápidamente, buscaron establecer acuerdos con el nuevo paradigma político y económico que asomó en el país: el desarrollismo (Carri, 1967).

\section{E1 accionar de la clase obrera bajo el desarrollismo}

En 1958, en un marco electoral irregular, el presidente Arturo Frondizi asumió la primera magistratura del país. A pocos meses de iniciar su mandato, comenzó a instrumentar su principal designio de gobierno: cambiar de manera sustancial el régimen social de acumulación de capital. Para lograr tal propósito era necesario establecer un marco de mutua colaboración entre empresarios y líderes sindicales.

En función de estos objetivos impulsó una activa política industrial favorable al complejo automotriz, metalúrgico y químico, a partir de una amplia y generosa participación del capital foráneo en las inversiones. Ahora bien, como correlato de ello, el empresariado insistió en sus demandas en el mundo laboral; en particular, las referentes a los ritmos de producción y al papel y las atribuciones de los representantes obreros en las fábricas. En ese sentido, el gobierno buscó la colaboración de los dirigentes gremiales peronistas, sobre todo los enrolados dentro de las 62 Organizaciones. Para conformar ese andamiaje, el presidente dispuso diversos aumentos de haberes, cesó con las intervenciones sindicales y retornó a la Ley de Asociaciones Profesionales que pautaba el reconocimiento legal de una sola entidad en cada industria. Sin embargo, este panorama duró pocos meses.

A fines de 1958, Frondizi impulsó una serie de medidas económicas (privatizaciones, devaluación de la moneda, aumento de tarifas) junto con una favorable política de apertura hacia los capitales externos que, 
en conjunto, apuntaban a consolidar su plan nodal de gobierno. En consecuencia, se intentó cambiar las relaciones laborales en el interior de las fábricas, objetivo que algunos sectores de la clase dominante anhelaban implementar desde la segunda presidencia de Perón. Esto derivó en un escenario de mayor conflictividad social. En este contexto, la huelga semiinsurreccional que se produjo tras el conflicto de los obreros del frigorífico Lisandro de la Torre, en enero de 1959, marcó el punto de inflexión más significativo entre el movimiento laboral y el mandatario desarrollista (Salas, 1990; González, 1996).

Si bien en el transcurso de 1959 se produjo un incremento en la cantidad de huelgas, con un alto número de jornadas no laborables, las mismas se dieron en un particular contexto político y económico. En lo inmediato, la fuerte ofensiva gubernamental sobre la clase trabajadora se tradujo en una retracción del nivel de la actividad productiva. En forma paralela, el primer magistrado no titubeó en emplear las fuerzas de seguridad (movilizaciones militares, detención de obreros, procesamiento por medio de la jurisdicción castrense) para garantizar su programa desarrollista.

En esta coyuntura se deben analizar las jornadas perdidas de ese año. Las medidas de fuerza continuaron, pero en un contexto defensivo, sobre todo a partir del fracaso de la huelga general de enero de 1959 . La clase obrera tuvo que reclamar tanto por aumentos salariales como por la defensa de la fuente de empleo. A esto se sumó una burocracia que no estaba dispuesta a perder sus privilegios, otorgados por la ley de Asociaciones Profesionales (junto con el control de sus entidades) y en el marco de un mercado laboral afectado por una fuerte recesión. En este sentido, fue notable que las empresas, por lo general, no se alarmaran ante los embates de los asalariados; los aceptaron con cierto beneplácito y tampoco mostraron deseos de solucionar las dificultades por vias pacíficas. La falta de voluntad negociadora de los sectores del capital se reflejó, además, en la extensa duración de las medidas de fuerza (frigorífico Lisandro de la Torre, bancarios, metalúrgicos, químicos, textiles); factor que ayuda a explicar, en relación con los años anteriores, cómo en 1959 hubo un número menor de huelgas, pero con una mayor cantidad de jornadas perdidas.

En el contexto económico y político ya indicado, se buscó incluir ciertas pautas reguladoras de la actividad productiva en los convenios colectivos. O bien, en algunos casos, si éstos se hallaban formulados de manera ambigua, se los quería modificar para adaptarlos a las nuevas circunstancias. De este modo, los convenios colectivos de trabajo, a partir de 1960, buscaron una mayor racionalización de las labores, un incremento en los ritmos de producción y una modificación de las categorias existentes. En consecuencia, en algunas ramas industriales 
se firmaron acuerdos que beneficiaron al empresariado, como textiles y carne. Sin embargo, no se puede concluir que estos resultados hayan sido similares en todas las otras negociaciones; por ejemplo, el panorama dentro de los metalúrgicos resultó distinto.

La situación de este gremio, por su ubicación en el sistema productivo y por su importancia política en el conjunto de la clase trabajadora, representa una interesante muestra para analizar. En particular, los resultados que se desprenden en torno de tres cuestiones discutidas durante las negociaciones del convenio colectivo $\mathrm{N}^{\circ}$ 55/60: la incorporación de nuevas pautas de producción, la eliminación de trabas que afectaban a la productividad y la definición y la limitación del poder de las comisiones internas en el ámbito fabril.

Al respecto, cabe observar que, más allá de la ambigüedad de la redacción de algunos de sus artículos, no se puede deducir que éstos representaron una "profunda derrota de la clase obrera" (James, 1990: 340). Por el contrario, en nuestra opinión, el empresariado no logró los objetivos propuestos. Las relaciones de fuerza entre las clases y sus enfrentamientos, en cada coyuntura histórica, determinaron -en última instancia- la posibilidad real de aplicar los esquemas de incentivos. De este modo, la viabilidad de aplicar los cambios en el sistema de productividad dependió tanto del propio desarrollo fabril como de las necesidades de un mercado en expansión. En cuanto a la incorporación de cláusulas referidas a la movilidad, éstas no fueron establecidas en la paritaria metalúrgica, sino que continuó el pago de acuerdo con las categorias previamente designadas. Por último, a diferencia del convenio de 1949, la nueva reglamentación aceptó la presencia de las comisiones internas y de los cuerpos de delegados. De esta manera, se validó su presencia jurídica y su poder en la discusión de los problemas laborales en el seno de los talleres y de las fábricas.

Las medidas políticas adoptadas por Frondizi impactaron en las condiciones materiales de vida de la clase trabajadora. En un escenario altamente recesivo, no sólo se tuvo que reclamar por dificultades salariales sino también por el resguardo de las fuentes de empleo.

En lo que concierne al movimiento obrero, tradicionalmente, este lapso ha sido definido como un período de derrota y desmovilización. Sin embargo, la realidad fue mucho más rica y compleja. La mayoría de los ensayos que analizaron el período, basándose sólo en las estadísticas proporcionadas por la cartera laboral para Capital Federal (Ministerio de Trabajo y Seguridad Social, 1961), consideraron que la conflictividad obrera fue escasa. Por el contrario, no fue así; si se observan otras fuentes como diarios nacionales, locales, prensa partidaria, testimonios orales, entre otros, se demuestra una conclusión distinta de dicha apreciación. Si bien es cierto que la contracción del mercado de traba- 
jo (evidenciada desde mediados de 1959 hasta fines de 1962) ayudó a que las huelgas propiamente dichas $-\mathrm{y}$ registradas oficialmente como tales-disminuyesen, esto no invalida advertir la existencia de protestas expresadas bajo diferentes formas. Tanto el proletariado fabril como los asalariados del sector terciario, en ese orden, llevaron a cabo numerosos enfrentamientos. Otro dato revelador es que se desplegaron al margen de su agrupamiento sindical, es decir, tanto de las entidades enroladas dentro de la esfera de las 62 Organizaciones como bajo el ámbito de los gremios denominados como Independientes.

Conforme a lo investigado (Schneider, 2006), el mayor número de conflictos fue originado como consecuencia de la situación recesiva en el campo manufacturero. En este tipo de reclamo estuvieron implícitos dos procesos en juego. En primer lugar, las medidas implicaron una clara defensa de la fuente de empleo. En segunda instancia, las protestas indicaron un alto componente de solidaridad con el trabajador despedido o suspendido, ya fuese por motivos económicos, gremiales o políticos. En un sinnúmero de circunstancias, las acciones se fundamentaron en principios de compañerismo. Esto cobra aún más relevancia si se tiene en cuenta la firme actitud ofensiva de la presidencia de Frondizi y los principales grupos empresarios. Un segundo motivo de pugna se suscitó alrededor de las negociaciones por la renovación de los convenios colectivos de trabajo. En esas pujas no sólo se discutieron incrementos salariales para los distintos escalafones, categorias o tareas. En intima conexión con ello, se produjeron reclamos vinculados a las interpretaciones que reglamentaban los convenios colectivos laborales. En cuanto a la metodología de enfrentamiento, predominaron los paros por veinticuatro horas junto con ceses de tareas parciales de tres y cuatro horas por turno. En ocasiones, estos últimos tendieron a convertirse en progresivos. También se efectuaron medidas de fuerza a través de trabajos a reglamento, a desgano y quites de colaboración.

Cabe destacar que las medidas fueron llevadas adelante a partir de las propias instancias de base en cada lugar de trabajo. La dirigencia de los grandes gremios sólo acompañó formalmente algunos de esos reclamos; su objetivo central fue evitar que sus entidades fuesen intervenidas por el gobierno. La huelga que protagonizaron los ferroviarios en el segundo semestre de 1961 fue una fiel muestra de lo anterior.

Como ha sido analizado en otros lugares (Cena, 1998; Schneider, 2006), esta huelga se originó a raíz de las políticas de racionalización y privatización del sistema de comunicaciones impulsadas por el mandatario desarrollista. En dicha ocasión, el conflicto fue motorizado por las asambleas de base y por dirigentes de las seccionales de los dos principales gremios del riel: la Unión Ferroviaria y La Fraternidad. Previo al mismo, como en muchas otras oportunidades, los jefes laborales 
desautorizaron con intimidaciones algunas medidas de fuerza adoptadas por las seccionales. En el caso de la protesta de 1961 el desempeño de los jerarcas y los trabajadores quedó claramente contrastado. Mientras los directivos de las principales organizaciones mantuvieron una actitud de negociación y cautela, los trabajadores desplegaron las acciones con un alto grado de autonomía, enfrentando la represión gubernamental, conformando distintas comisiones (solidaridad, difusión y prensa, búsqueda de alimentos, seguridad, etc.) que permitieron extender la confrontación durante más de cuarenta días.

En cuanto al comportamiento de los jerarcas gremiales, la evidencia analizada sugiere una conclusión diferente de la comúnmente aceptada. Sobre este proceder, James afirmó que "el cansancio y la desmoralización" de los activistas, producto de las derrotas ocurridas en 1959, fueron el "telón de fondo de un proceso de burocratización" y de "una creciente corrupción de los dirigentes" (James, 1990: 168-174). Por el contrario, los datos expuestos en nuestra investigación indican que la conducta de la burocracia de esos años fue consecuencia de una combinación de elementos de continuidad y de ruptura con el período anterior. Recuperados los sindicatos, los principales referentes laborales priorizaron su defensa y los réditos que éstos dejaban. La actitud que mantuvieron frente a los conflictos evidenció la manera en que los intereses corporativos incidieron en su comportamiento. Dichos hombres fueron producto de una nueva situación estructural enmarcada tanto por el proceso manufacturero del desarrollismo (y los beneficios que generaba mantener buenos contactos con el gobierno nacional) como por la capitalización política que lograron durante las pugnas contra la Revolución Libertadora. Por último, es útil observar que, aún en los momentos más difíciles, Frondizi no suspendió el diálogo con los jefes gremiales ni les caducó su mandato como sí lo hizo Aramburu.

En consonancia con lo anterior, a diferencia de algunas afirmaciones que aseveran que los jefes laborales mantuvieron un fuerte control sobre sus afiliados (James, 1990: 175), nuestra pesquisa sostiene que -en numerosas circunstancias- aquéllos fueron cuestionados, teniéndose que valer de ciertas maniobras (políticas, jurídicas, coercitivas) para preservar su espacio de poder. La situación vivida por Andrés Framini en el gremio textil, por ejemplo, fue una clara prueba de las vicisitudes que tuvo que sortear la dirigencia para mantener el control de la entidad laboral. En 1961, el mencionado dirigente tuvo que recurrir al apoyo directo del Ministerio de Trabajo para poder continuar al frente de su sindicato (Schneider, 2006: 160-164).

En idéntico sentido, fue precisamente esa capacidad de movilización que tuvo la clase trabajadora la que permitió constituir el núcleo central del vandorismo: la presión junto con la negociación. En otras palabras, 
para desplegar tal proceder los líderes gremiales se valieron de dicha potencialidad: si la dirigencia sindical fue reconocida durante esos años como un factor de poder en todos los escenarios políticos en los que se presentó, fue justamente porque contaba con el respaldo de un fuerte movimiento obrero que se hallaba movilizado.

\section{Las ocupaciones fabriles: una protesta generalizada durante la gestión radical}

Los acontecimientos ocurridos durante la gestión desarrollista tuvieron un efecto inmediato en el comportamiento de la clase trabajadora y en el resto de los actores sociales durante los siguientes años. A pesar de las vicisitudes que provocaron los enfrentamientos armados entre Azules y Colorados, durante la presidencia de facto de José M. Guido entre 1962 y 1963, la actividad huelguística continuó en gran parte por fuera de la cúpula sindical. En un escenario de recesión industrial, las principales demandas obreras giraron en torno a los despidos, las suspensiones y el atraso en el cobro de haberes. Si bien se desplegaron diferentes tipos de medidas de fuerza (paros, trabajos a reglamento, quites de colaboración), las ocupaciones de fábrica, algunas de ellas con rehenes, empezaron a generar cierta preocupación y malestar entre los sectores dominantes por su radicalización y eficacia.

Las ocupaciones fabriles - para tener cierta efectividad- se desarrollaron con el empleo de rehenes. Para los empresarios, dicha metodología planteó la negociación (por las condiciones del personal retenido) antes que el desalojo policial. De este modo, las tomas de fábrica comenzaron a convertirse no sólo en una herramienta efectiva en el reclamo de los trabajadores sino que también sirvieron de instrumento de conversación y de amenaza velada por parte de la burocracia para pelear su lugar en diferentes espacios de poder. Sin embargo, corresponde indicar que, a grandes rasgos, estas acciones se desplegaron al margen de la cúpula sindical.

Con este panorama de fondo, en enero de 1963 se decidió finalizar con la intervención de la CGT. Sobre la base de un explícito acuerdo entre las 62 Organizaciones y los gremios Independientes, se produjo el Congreso Normalizador de la central obrera, eligiéndose una nueva conducción encabezada por José Alonso, aunque el verdadero poder lo ostentó el metalúrgico Vandor. En ese evento se anunció un plan sistemático y permanente de lucha en torno a la libertad de los detenidos por razones politicas, la vigencia de las leyes de previsión social, la participación de los trabajadores en la dirección de las empresas, la fijación de precios máximos para los artículos de primera necesidad, la reforma agraria, la anulación de contratos petroleros y el retorno a la 
Constitución Nacional. De este modo, se ordenó una primera semana de paros para mayo de 1963, en el marco de la primera etapa del Plan de Lucha.

Este escenario de huelgas y reclamos se profundizó con la llegada a la presidencia de Arturo Illia. A los pocos meses de su gestión, el joven gobierno tuvo que hacer frente a un nuevo enfrentamiento de la central laboral. Además de las anteriores demandas, se agregó el pedido de que la administración radical sancione la ley del salario mínimo, vital y móvil. Así, a través de sucesivas jornadas, se dispuso la realización de la segunda etapa del Plan de Lucha por medio de una masiva ocupación de establecimientos laborales en todo el país. En forma planificada, durante mayo y junio de 1964, se tomaron con rehenes once mil empresas, en la que participaron activamente cerca de cuatro millones de trabajadores. La protesta no sólo resultó impactante por la cantidad de obreros y fábricas involucradas sino también por el estado asambleario que se vivió en los lugares de trabajo, por las condiciones de clandestinidad en que fue organizada la medida y porque se quebró la disciplina fabril en forma masiva.

Concierne subrayar que el éxito de este tipo de enfrentamiento dependió de la amplia intervención de los asalariados, por medio de sus delegados y comisiones internas que no habian sido derrotados bajo la Revolución Libertadora ni con el desarrollismo. Una de las características que más destacaron tanto cronistas contemporáneos como investigadores posteriores fue el alto grado de planificación, precisión y clandestinidad que comportaron las ocupaciones. Los jefes de la CGT dispusieron, para que la protesta fuese efectiva, que los establecimientos encargados de ejecutar la medida no se conocieran hasta último momento, para mantener el carácter sorpresivo y conspirativo; recién entonces se entregaban los "sobres cerrados" a las comisiones internas y los cuerpos de delegados que instrumentaban la toma. Además, al margen de las disposiciones y del organigrama planificado por la confederación laboral, hubo numerosas ocupaciones de fábricas, talleres y universidades que no estuvieron previstas y que emergieron como corolario de estos enfrentamientos.

Numerosos analistas, entre otros Rubén Rotondaro (1971), dieron a entender que la efectividad de la protesta gremial se debió a al férreo control que tuvo la burocracia de la CGT. Frente a esa afirmación, nuestra opinión considera que el éxito fue consecuencia de la experiencia adquirida desde la Resistencia y, sobre todo, a partir del empleo sistemático de las ocupaciones de fábrica como metodología de lucha. En este sentido, es evidente que la central laboral dispuso esta medida de fuerza a partir de una forma de enfrentamiento que, para ese entonces, se había generalizado entre la clase obrera. 
Por otra parte, si bien los aspectos específicos de cada toma fabril variaron, como es lógico, de un establecimiento a otro, resulta pertinente identificar ciertos elementos comunes; entre éstos, uno de los más significativos fue el quiebre de la obediencia laboral frente a los empresarios. De este modo, un fenómeno que estuvo presente, no sólo en estas ocupaciones sino también en otras (previas y posteriores), fue la iniciativa obrera de continuar con el proceso de manufactura. La puesta en funcionamiento de las máquinas, junto con el empleo de rehenes, implicó una significativa sensación de inseguridad dentro de las esferas del poder político y económico.

Esta situación no era sólo un problema en cuanto a un claro perfil simbólico, al alterarse la habitual disciplina patrón-obrero por la de obrero-patrón, sino que existieron otros argumentos más profundos. Sobre el particular, en dicha coyuntura, se destacaron dos cuestiones al respecto. La primera fue que se ponía en discusión la propiedad privada y la puesta en producción de las empresas; la segunda, la posibilidad de que la medida en sí misma engendre un proceso de dificil sujeción. En este sentido, algunas tomas se extendieron un par de jornadas después de finalizado el operativo de la CGT, debido a que, en algunos lugares, los operarios tenian otras cuestiones pendientes con sus respectivas patronales que estaban al margen de los reclamos del Plan de Lucha, confesando un alto grado de autonomía gremial.

En forma paralela, es importante considerar que, si bien la puesta en práctica de cualquier método de lucha implica una alta cuota de organización y de disciplina, la ocupación con rehenes en las instalaciones fabriles fue un tipo de enfrentamiento donde estas cualidades se hicieron más necesarias que en otras acciones. La misma implicaba la planificación de la vida de los obreros y de los rehenes mientras se estaba adentro. Tareas tales como las guardias, la autodefensa, la búsqueda de comida y su posterior distribución, la divulgación del acontecimiento y el pedido de solidaridad con las fábricas y barrios adyacentes, fueron labores imprescindibles que se debian contemplar para que la protesta resultara efectiva. La ocupación, junto con una sólida unidad para la acción, requería de una amplia democracia obrera, por medio de reuniones permanentes, para obtener un cabal convencimiento de las tareas que se llevaban a cabo. Las fuentes y los testimonios consultados ilustraron, en muchas ocasiones, el "estado de asamblea" que reinaba durante un conflicto.

La gimnasia de tomas de fábrica, aún conducidas por la CGT, tuvo el efecto de politizar (por momentos) a muchos trabajadores hacia posturas radicalizadas. No sólo por la experiencia, también porque una actitud combativa generaba espacios y puntos de contacto con militantes peronistas y de corrientes de izquierda. Las jornadas de protesta permi- 
tieron que los trabajadores transiten de una lucha sindical a una lucha política que englobe al conjunto de la clase obrera. Las reivindicaciones planteadas, las acciones llevadas a cabo (toma de rehenes, quiebre de la disciplina fabril) así como los enfrentamientos con los aparatos represivos del Estado (policía y jueces) condujeron a que embrionariamente se cuestionara el propio sistema social, económico y político de explotación del capital. De este modo, la propia central sindical se movió en forma cautelosa durante varias semanas, evitando disponer un enfrentamiento donde ella también resultara perjudicada; se temía que la acción, por su dinámica, pudiese llegar a objetar su propia existencia. En sintesis, para distintos voceros de la clase dominante, entre ellos la jerarquía de la Iglesia Católica, fue alarmante la capacidad de acción de la clase obrera que podía movilizarse hacia metas diferentes de las declaradas por la entidad cegetista.

Como consecuencia inmediata de estos acontecimientos, las medidas dispuestas por la CGT tendieron de ahí en más a atemperarse. Por otra parte, a diferencia de lo sucedido en la primera mitad de la década, los trabajadores priorizaron las huelgas, los sabotajes y los paros parciales a la hora de hacer sentir sus reclamos; estos últimos, dirigidos por las comisiones internas y los cuerpos de delegados, se concentraron en torno a pedidos de mejoras salariales.

No obstante, la preocupación de los sectores empresariales por las tomas continuó estando presente; a su vez, sirvió como justificación durante el golpe de estado de 1966. Desde hacía más de una década que la clase dominante no lograba estabilizar la situación económica y política mediante un proyecto coherente de acumulación de capital y de inserción en la nueva división internacional del trabajo surgida tras la Segunda Guerra Mundial. Para alcanzar tales fines, debia imponerse sobre el movimiento obrero, en particular sobre sus organismos de base fabril. Éstos se habían convertido en un serio obstáculo para gran parte de la burguesía en su proceso de optimización del capital. De ahí el alcance y el significado de esta nueva intervención militar, que fue diferente, en sus metas y su violencia, de otras asonadas castrenses (O’Donnell, 1996).

\section{Oposición y reorganización de los trabajadores en la Revolución Argentina}

La dictadura de Juan C. Onganía intentó -no sin debates en su seno- establecer un nuevo reordenamiento en el mundo del trabajo. Para eso se propuso, por un lado, detener la conflictividad social existente, mientras que, por otro lado, quiso establecer una corriente sindical cercana a sus principios ideológicos. 
En líneas generales, el movimiento obrero presentó un doble comportamiento frente al gobierno. Por un lado, la dirigencia gremial mantuvo un claro proceder negociador, evitando la intervención sobre las entidades laborales, alineándose con algunas ideas y sectores del régimen castrense. Por el contario, otra fue la actitud de numerosas organizaciones de base, que en diferentes circunstancias mantuvieron una actitud de confrontación frente al avasallamiento de sus derechos.

Sobre la primera cuestión, se debe mencionar que hubo varios acuerdos firmados con distintos líderes laborales: desde los que avalaron la reunificación de la CGT, pasando por la paritaria de los metalúrgicos de 1966, hasta el nacimiento de una nueva tendencia sindical (la Nueva Corriente de Opinión) que simpatizaba con los postulados ideológicos de la dictadura.

En lo que concierne al segundo punto, ante la embestida económica y la represión, las comisiones internas y los cuerpos de delegados se encargaron de la defensa de las conquistas laborales. Así, por ejemplo, en el conflicto portuario del último trimestre de 1966, la protección contra la medida de racionalización quedó en manos de las organizaciones de base como fue la Coordinadora de Comités de Resistencia de Barrios y Hoteles, frente a la deserción de la cúpula encabezada por Eustaquio Tolosa. Esta Coordinadora, que pasó a ser denominada "Intervillas", creó varias subcomisiones que se encargaron de recolectar ayuda solidaria para el fondo de huelga y comida para los portuarios, junto con la organización de grupos que se ocuparon de difundir la lucha y frenar las actividades de los esquiroles. Intervillas publicó dieciséis Boletines de Huelga y numerosos volantes; a su vez, intentó sumar a la medida de fuerza a los ferroviarios, que por aquel entonces comenzaban a sentir la política de privatización del régimen.

En esa coyuntura hubo diversas medidas de fuerza en defensa de los derechos adquiridos; si bien se originaron en forma aislada, las mismas intentaron detener la ofensiva empresarial de incrementar los ritmos de producción y de modificar las categorias laborales. En su mayoria, las pugnas gremiales se realizaron en el lugar de trabajo, fueron de breve duración y se ejecutaron en forma rápida y sorpresiva, a través de quites de colaboración y paros por turnos. De manera frecuente, se organizaron al margen de los jerarcas, por medio de reuniones clandestinas en las fábricas, charlas en las secciones y con cierta difusión en las carteleras de las plantas; de este modo, lentamente, fue aumentando el divorcio entre las organizaciones de base y el liderazgo sindical.

En ese escenario, el régimen militar desarticuló (a través de un conjunto de medidas tanto económicas como represivas) la conducción de la central obrera; como consecuencia, se fueron expresando distintas actitudes frente a la dictadura. Con el transcurso del tiempo, estas 
posturas se cristalizaron en dos confederaciones laborales: la CGT de los Argentinos y la CGT Azopardo.

Por fuera de estos reacomodos internos, la clase obrera prosiguió con la defensa de sus conquistas laborales en forma aislada y atomizada. La resistencia a la sólida ofensiva empresarial cobró un notable significado porque se desarrolló por fuera y en contra de la conducta de los burócratas sindicales, quienes, como parte de su estrategia de alineamiento con el gobierno, en varias oportunidades denunciaron y delataron a los activistas que se rebelaban a sus mandatos (Walsh, 1986: 148-152). Por ende, los obreros debieron mantener una actitud de resguardo ante los supervisores, el personal jerárquico y, algunas veces, frente a sus "representantes laborales".

En sintesis, tanto las rigurosas condiciones de labor como el papel desempeñado por la dirigencia sindical llevaron a abrazar nuevas formas de lucha y resistencia. De este modo, hubo una particular organización clandestina en las unidades de producción para poder programar y efectuar acciones independientes de los habituales canales orgánicos. La combinación y la minuciosa concertación de estos hechos -en un entorno represivo- implicaron la existencia de un respetable nivel de organización y de conciencia de clase gremial, cuestión que poco tiempo después mostró su verdadero alcance.

\section{La conflictividad obrera demuele a la dictadura}

Este multifacético proceso, en el que se combinaron problemas de índole laboral con tensiones latentes en la sociedad, dio origen al Cordobazo en mayo de 1969. Cabe insistir que en esa particular coyuntura convergieron aspectos puntuales (locales y nacionales) con fenómenos que se remontaban a 1955 (Brennan, 1996; Gordillo, 1997; Cena, 2000).

A partir de entonces, la mayoria de los líderes sindicales quedaron desbordados por sus bases. Se produjo un profundo corte horizontal con las conducciones gremiales en el ámbito de las organizaciones de tercer grado. Todas las corrientes anteriormente aludidas se hallaron objetadas. En primer lugar, la burocracia participacionista profundizó su aislamiento de la clase trabajadora; en segunda instancia, se aceleró la disolución de la CGT de los Argentinos. Por último, los azopardistas intentaron -con la ayuda del Poder Ejecutivo- acomodarse en la nueva escena nacional; sin embargo, no lo lograron: el fuerte contenido antiburocrático de la protesta impidió este objetivo.

En otros términos, se inició un auge de acciones donde los trabajadores obtuvieron triunfos y derrotas en este proceso. Pero, por sobre todo, de las experiencias se extrajo un vital aprendizaje que se cristalizó en la combatividad gremial del primer lustro de la década de 1970. 
Si bien las movilizaciones y los conflictos en las provincias provocaron una evidente lesión en las instituciones de la Revolución Argentina, no fue menos determinante el proceso experimentado por el proletariado industrial de la Capital Federal y el conurbano bonaerense. En dicha área, los enfrentamientos obtuvieron parte de las demandas laborales reclamadas; en una coyuntura de efervescencia social, los empresarios se encontraron obligados a conceder subas salariales y otras prerrogativas a los trabajadores.

Por otro lado, corresponde observar que pese a que muchos conflictos terminaron sin obtener los reclamos planteados, dejaron un notable saldo organizativo, tanto para aquellos que participaron como para el resto de la clase trabajadora que los observó. Cada enfrentamiento sirvió como un cúmulo de experiencia y nutrió las futuras protestas. En esa perspectiva fueron madurando comisiones internas, cuerpos de delegados y activistas que, por la propia dinámica, empezaron a adoptar medidas de fuerza más profundas. Gradualmente, mientras crecía un abierto sentimiento de rechazo a la burocracia, los distintos órganos del movimiento obrero comenzaron a convertirse en instrumentos de lucha alternativos y radicalizados.

Los paros activos con abandono de los lugares de trabajo, las asambleas autoconvocadas, las manifestaciones en las calles, las ocupaciones fabriles con rehenes, el desconocimiento y el relevo de las cúpulas gremiales fueron sus expresiones más sustanciales. Al compás de ese proceso de agitación social, nació el clasismo. En esos años, el modelo más trascendente de ese comportamiento obrero fue el desarrollado por SITRAC-SITRAM en las plantas cordobesas de Fiat-Concord y FiatMaterfer.

Los trabajadores de estos sindicatos condensaron, en su breve existencia, los elementos que identificaron al clasismo como tendencia en el seno de la clase trabajadora: la realización de asambleas en las plantas fabriles, las manifestaciones callejeras y el enfrentamiento contra el régimen castrense, el capital y la cúpula laboral. El clasismo representó un corte horizontal con la jefatura burocrática, en tanto que su forma de pensamiento escapó al chaleco ideológico del peronismo virando hacia el marxismo. La participación de las bases obreras en la discusión de los problemas relacionados con las condiciones de producción (organización técnica, autoridad de la empresa en el manejo productivo) hizo, por su propia dinámica, que naciera un modelo alternativo de conducta y acción gremial. Sin embargo, el clasismo no sólo representó esta instancia democrática: más significativo fue el hecho de que las organizaciones integrantes de esta corriente elaboraron un programa que abiertamente se planteaba el derrocamiento de la dictadura y el enfrentamiento tanto contra la burguesía como contra la dirigencia sindical. 
El surgimiento de esta perspectiva ideológica expresaba la ruptura y la superación no sólo de las variantes participacionistas y vandoristas sino también la de aquellos posicionamientos laborales que erigian un discurso radicalizado. En estos puntos su mirada se alejaba de otras corrientes politicas y gremiales (como el peronismo combativo, la CGT-A, el sindicalismo de liberación de Agustín Tosco) que consideraban a la burocracia como un fenómeno ideológico o corrupto, que sólo se modificaba con un cambio de líderes. Por el contrario, el clasismo sostuvo que la burocracia era un conjunto de personas con intereses materiales concretos, apoyados en última instancia en un Estado que los legitimaba (con el empleo de leyes y la administración de las obras sociales) a cambio de negociar con la patronal. Para esta tendencia, la cúpula sindical se encargaba de perpetuar y garantizar la explotación del capital sobre los trabajadores. En este sentido, el clasismo fue partidario de la total ruptura con las entidades gremiales junto con la idea de que los trabajadores se organizaran en forma independiente, sin ningún tipo de tutela estatal. Por otro lado, en términos políticos, se opuso a aquellos partidos que propugnaban una institucionalización de los conflictos de clase; en sintonía con ello, se declaraba a favor de la lucha anticapitalista por el socialismo.

Por otro lado, este fenómeno tuvo un fuerte componente juvenil. La mayor parte de sus integrantes estaban realizando sus primeras prácticas de militancia sindical (y de alguna manera, también política), hecho que le permitía tener cierta independencia de los manejos burocráticos. De este modo, las nuevas comisiones internas fueron seguidas y respetadas no tanto por su ideología, sino por su conducta en el desenvolvimiento gremial. El clasismo, como ideario que hacía un profundo énfasis en la independencia de la clase obrera de cualquier otra instancia social ajena a ella, comenzó a convertirse en un elemento cotidiano, con la propia práctica, en la conciencia de los trabajadores. Por otra parte, la adquisición de ese comportamiento no expresó una predisposición generalizada para conseguir el poder político ni que los obreros abrazaran las ideas socialistas. Dicho de otra manera, la experiencia de SITRAC-SITRAM no fue un fenómeno que abarcó al conjunto del movimiento obrero (Duval, 1988; Flores, 1994).

Recapitulando, fue innegable el lento pero continuo surgimiento de una nueva camada de representantes gremiales de base. A partir de los acontecimientos de mayo de 1969 se quebró una tendencia predominante, durante un cuarto de siglo, donde los integrantes de las comisiones internas y las oposiciones sindicales fueron generalmente peronistas. Si bien en ese intervalo, sobre todo entre 1955 y 1969, hubo direcciones laborales de izquierda, el Cordobazo abrió el camino para la propagación de un activismo más radicalizado. Este fenómeno no surgió de la nada, 
sino que fue producto de una maduración, en función de la experiencia, que hizo la clase trabajadora en el lapso antes mencionado. Se abrió una nueva etapa en las formas de oposición de la clase trabajadora, donde el empleo de la violencia (tanto guerrillera como popular) se convirtió en algo frecuente. Además, surgió por primera vez la violencia contra la cúpula laboral incluyendo la muerte de burócratas a manos de sus contrarios peronistas. El ascenso de la clase obrera impactó en el desarrollo de las ideas y de las organizaciones de izquierda. Aunque la labor de éstas, en los años previos, contribuyó en algún grado al estallido de estas movilizaciones, su espacio aumentó en forma significativa luego de esos acontecimientos. Sin embargo, es lícito observar que la conformación de este activismo no se trasladó de manera mecánica a la creación de un fuerte partido que promueva la independencia política de los trabajadores y que abogue por el socialismo. Por el contrario, los hechos posteriores mostraron una profunda identificación de la mayoria de los obreros industriales con la figura de Perón.

En esa coyuntura, el general Alejandro A. Lanusse se autoproclamó primer mandatario. Su presidencia no buscó cumplir con las metas anheladas en 1966 sino, por el contrario, intentó negociar un repliegue del régimen de facto lo menos traumático posible. Frente al importante sentimiento antimilitarista existente, mediante el cual se estaban trastocando los cimientos de la dominación social, el nuevo gobierno (con la colaboración de los políticos que encabezaban la Hora del Pueblo y el Encuentro Nacional de los Argentinos) se propuso absorber el descontento con la convocatoria a elecciones. Para lograr dicha meta se instrumentó un complejo sistema de alianzas coyunturales y componendas politicas junto con el empleo del terrorismo de Estado.

A pesar del esfuerzo por institucionalizar el descontento existente, las protestas obreras y estudiantiles junto con el accionar de las organizaciones armadas continuaron durante el período. El fracaso de la propuesta conciliatoria de Lanusse obligó a la clase dominante a recurrir, una vez más, a Perón como la única personalidad con suficiente peso político para revertir lo que se visualizaba como un sostenido avance revolucionario.

En esa coyuntura extendida de enfrentamientos gremiales y de impugnación masiva, el líder justicialista empezó a responder, de manera favorable, a ciertos requerimientos y propuestas de las Fuerzas Armadas. Esta posición, en torno de la búsqueda de la pacificación social, fue la dominante en las declaraciones públicas de ese momento y, primordialmente, en el carácter que le dio a su regreso al país luego de diecisiete años de destierro y proscripción. De esta manera, el anciano general comenzó a destacar sus propósitos de contener el conflicto social y de absorber a las heterogéneas tendencias que proclamaban la adhesión a 
su liderazgo. Por otra parte, esto conduce a reflexionar acerca del hipotético éxito de esta propuesta política. El incremento de la conflictividad obrera durante los gobiernos peronistas de 1973-1976 indica que sus objetivos no triunfaron.

\section{Una breve conclusión}

Como se ha observado en las páginas anteriores, corresponde señalar que, si bien de manera efectiva hubo una fuerte ofensiva laboral durante esos años, ésta no obtuvo los resultados propuestos por los sectores hegemónicos de la clase dominante. A pesar del contexto represivo, no se concretó la anhelada fragmentación de la clase obrera debido -entre otros motivos- al significativo nivel de conciencia gremial que poseyeron los trabajadores. En el transcurso de esas décadas, los cuerpos de delegados y las comisiones internas continuaron disputando, en el seno de los talleres y de las fábricas, el poder al capital. Por otra parte, en diversas circunstancias, la dinámica y la autonomía que adquirieron las organizaciones de base fueron también un motivo de preocupación para una dirigencia sindical que buscó someter a sus entidades.

Dentro de este escenario, no se perdieron todas las conquistas laborales, como anhelaron vastos sectores de la burguesía y distintos funcionarios gubernamentales. Los obreros durante la década del 60 continuaron teniendo una importante participación en la redistribución del ingreso, mantuvieron los niveles de ocupación laboral y practicaron numerosas protestas que cuestionaron en más de una ocasión los intereses del establishment. Más aún, en el marco de esas pugnas, los trabajadores fueron adquiriendo una mayor experiencia en su organización y, por lo tanto, en su conciencia. Corresponde subrayar que este no fue un proceso lineal, sino que hubo avances y retrocesos. El Cordobazo, el clasismo y las luchas del primer lustro de los 70 no se llegan a explicar si no se observa esta práctica previa.

En este sentido, los diversos instrumentos (legales y coercitivos) empleados bajo las administraciones peronistas de 1973 a 1976 no alcanzaron a tranquilizar la conflictividad obrera imperante, ni tampoco lograron resolver las quejas de los empresarios en torno a la disciplina laboral. La coyuntura más evidente de esta situación incontrolable para el capital fue reflejada por las jornadas de junio y julio de 1975 (Torre, 1893; Lobbe, 2006; Werner y Aguirre, 2007). El denominado Rodrigazo fue, quizás, uno de los puntos de inflexión que terminó de confirmar, para los sectores dominantes, la necesidad de aplicar un régimen de terror sobre la clase trabajadora como medio para lograr los objetivos propuestos en la década de 1950. El camino hacia la salida dictatorial ya estaba abierto, sólo faltaba el momento adecuado para hacerlo. 


\section{Bibliografia}

Brennan, James (1996), El Cordobazo. Las guerras obreras en Córdoba. 1955-76, Buenos Aires: Sudamericana.

Camarero, Hernán (2007), A la conquista de la clase obrera. Los comunistas y el mundo del trabajo en la Argentina, 1920-1935, Buenos Aires: Siglo XXI Editora Iberoamericana.

Carri, Roberto (1967), Sindicatos y poder en la Argentina. (Del Peronismo a la Crisis), Buenos Aires: Sudestada.

Cena, Juan Carlos (1998), El guardapalabras (Memorias de un ferroviario), Buenos Aires: La Rosa Blindada.

- (comp.) (2000), El Cordobazo, una rebelión popular, Buenos Aires: La Rosa Blindada.

Ceruso, Diego (2010), Comisiones internas de fábrica. Desde la huelga de la construcción de 1935 hasta el golpe de estado de 1943, Vicente López: PIMSA/Dialektik.

Doyon, Louise (1984), "La organización del movimiento sindical peronista, 1946-1955”, Desarrollo Económico. Revista de Ciencias Sociales, No 94, pp. 203-234.

-(2006), Perón y los trabajadores: los orígenes del sindicalismo peronista, 1943-1955, Buenos Aires: Siglo XXI Editora Iberoamericana.

Duval, Natalia (1988), Los sindicatos clasistas: SITRAC (1970-1971), Buenos Aires: CEAL.

Flores, Gregorio (1994), SITRAC-SITRAM. Del Cordobazo al clasismo, Buenos Aires: Magenta W.

Gilly, Adolfo (1986), "La anomalía argentina", Cuadernos del Sur, № 4.

González, Ernesto (comp.) (1999), El trotskismo obrero e internacionalista en la Argentina. Palabra Obrera, el PRT y la Revolución Cubana, , vol.1, Buenos Aires: Antídoto.

Gordillo, Mónica (1997), Córdoba en los ‘60. La experiencia del sindicalismo combativo, Córdoba: Universidad Nacional de Córdoba.

James, Daniel (1990), Resistencia e integración. El peronismo y la clase trabajadora argentina, 1946-1976, Buenos Aires: Sudamericana.

Lobbe, Héctor (2006), La guerrilla fabril. Clase obrera e izquierda en la Coordinadora de Zona Norte del Gran Buenos Aires (1975-1976), Buenos Aires: Ediciones ryr.

Ministerio de Trabajo y Seguridad Social (1961), Conflictos del trabajo, Buenos Aires.

O’Donnell, Guillermo (1996), El Estado burocrático autoritario. Triunfos, derrotas y crisis, Buenos Aires: E. de Belgrano.

Pozzi, Pablo y Alejandro Schneider (2000), Los setentistas. Izquierda y clase obrera, 1969-1976, Buenos Aires: Eudeba.

Rotondaro, Rubén (1971), Realidad y cambio en el sindicalismo, Buenos Aires: Pleamar. 
Salas, Ernesto (1990), La resistencia peronista: la toma del frigorífico Lisandro de la Torre, 2 vols., Buenos Aires: CEAL.

Schiavi, Marcos (2008), La resistencia antes de la Resistencia. La huelga metalúrgica y las luchas obreras de 1954, Buenos Aires: Editorial E1 Colectivo.

Schneider, Alejandro (2006), Los compañeros. Trabajadores, izquierda y peronismo, 1955-1973, Buenos Aires: Ediciones Imago Mundi.

-(comp.) (2009), Trabajadores. Un análisis del accionar de la clase obrera argentina en la segunda mitad del siglo XX, Buenos Aires: Ediciones Herramienta.

Torre, Juan C. (1983), Los sindicatos en el gobierno, 1973-1976, Buenos Aires: CEAL.

Walsh, Rodolfo (1986), ¿Quién mató a Rosendo?, Buenos Aires: Ediciones de la Flor.

Werner, Ruth y Facundo Aguirre (2007), Insurgencia obrera en la Argentina 1969-1976. Clasismo, coordinadoras interfabriles y estrategias de la izquierda, Buenos Aires: Ediciones IPS.

$$
* * *
$$

Resumen: El presente artículo indaga sobre el comportamiento de la clase obrera en los lugares de trabajo frente a la ofensiva patronal y gubernamental desarrollada entre 1955 y 1973. Como consecuencia, se explica cuáles fueron los principales objetivos que se plantearon los distintos gobiernos del periodo. De este modo se examina, a grandes rasgos, el accionar de las organizaciones de base. Asimismo, se analiza el papel de la dirigencia sindical ante estos hechos. En forma simultánea, se polemiza con una interpretación historiográfica que considera que, en esos años, los trabajadores se hallaban "derrotados" y "desmovilizados".

Palabras clave: Movimiento obrero - burocracia sindical - organizaciones de base - huelgas

Abstract: This paper delves into the behavior of workers in the shop floor between 1955 and 1973, facing both employers' and government's offensive. Consequently it explains the main goals that the various governments of the period had set themselves. It examines broadly the actions of grassroots organizations, and also analyzes the role of union leaderships in these events. Simultaneously, it debates with an historiographical interpretation that considers that in those years, workers were "defeated" and "demobilized".

Keywords: Labor movement - trade union bureaucracy - shop-floor organizations - strikes

Recepción: 18 de febrero de 2013. Aprobación: 16 de marzo de 2013. 